\title{
BMJ Open Prevalence of stroke, risk factors, disability and care needs in older adults in Singapore: results from the WiSE study
}

\author{
Wen Lin Teh, ${ }^{1}$ Edimansyah Abdin, ${ }^{1}$ Janhavi Ajit Vaingankar, ${ }^{1}$ Esmond Seow, ${ }^{1}$ \\ Vathsala Sagayadevan, ${ }^{1}$ Saleha Shafie, ${ }^{1}$ Shazana Shahwan, ${ }^{1}$ Yunjue Zhang, ${ }^{1}$ \\ Siow Ann Chong, ${ }^{1}$ Li Ling Ng, ${ }^{2}$ Mythily Subramaniam ${ }^{1}$
}

To cite: Teh WL, Abdin E, Vaingankar JA, et al. Prevalence of stroke, risk factors, disability and care needs in older adults in Singapore: results from the WiSE study. BMJ Open 2018;8:e020285. doi:10.1136/ bmjopen-2017-020285

- Prepublication history for this paper is available online To view these files, please visit the journal online (http://dx.doi org/10.1136/bmjopen-2017020285).

Received 1 November 2017 Revised 8 February 2018 Accepted 9 February 2018

Check for updates

${ }^{1}$ Research Division, Institute of Mental Health, Singapore, Singapore

${ }^{2}$ Psychogeriatrics, Changi General Hospital, Singapore, Singapore

Correspondence to Ms Wen Lin Teh;

Wen_Lin_TEH@imh.com.sg

\section{ABSTRACT}

Objectives The aims of the present study were to establish the prevalence of stroke, and to explore the association between stroke prevalence and sociodemographic and health factors, disability, cognitive functioning and care needs among older adult residents in Singapore.

Setting Data were drawn from the Well-being of the Singapore Elderly study - a cross-sectional epidemiological survey conducted from 2012 to 2013 on older adults living in Singapore.

Participants Participants were Singapore residents (citizens and permanent residents) 60 years and above who were living in Singapore during the survey period . Older adult residents who were institutionalised were also included in this study. Those who were not living in Singapore or who were not contactable were excluded from the study. The response rate was 65.6 $\%(2565 / 3913)$. A total population sample of 2562 participants completed the survey. Participants comprised $43.6 \%$ males and $56.4 \%$ females. The sample comprised $39.4 \%$ Chinese, $29.1 \%$ Malay, $30.1 \%$ Indian and 1.4\% other ethnicities .

Primary and secondary outcome measures History of stroke, along with other health and mental health conditions, disability and cognitive functioning, were determined by self-report.

Results Weighted stroke prevalence was $7.6 \%$ among older adults aged 60 and above. At a multivariate level, Malay ethnicity (OR $0.41, \mathrm{p}=0.012,95 \% \mathrm{Cl} 0.20$ to 0.82 ), hypertension (OR 4.58, $p=0.001,95 \% \mathrm{Cl} 1.84$ to 11.40 ), heart trouble (OR $2.45, \mathrm{p}=0.006,95 \% \mathrm{Cl} 1.30$ to 4.63$)$, diabetes (OR 2.60, $\mathrm{p}=0.001,95 \% \mathrm{Cl} 1.49$ to 4.53 ) and dementia (OR 3.57, $\mathrm{p}=0.002,95 \% \mathrm{Cl} 1.57$ to 8.12 ) were associated with stroke prevalence.

Conclusions Several findings of this study were consistent with previous reports. Given that Singapore's population is ageing rapidly, our findings may indicate the need to review existing support services for stroke survivors and their caregivers. Future research could investigate the association between various sociodemographic and health conditions and stroke prevalence to confirm some of the findings of this study.
Strengths and limitations of this study

- This study was based on a large nationwide population sample of 2562 older adult participants.

- An extensive list of sociodemographic and health factors of stroke were accounted for during multivariate regression analyses.

- Older adults who were institutionalised were represented in this study.

- This study examined self-reported stroke which may be subjected to errors such as false reporting resulting in overestimation or underestimation of stroke prevalence. As this is a cross-sectional study, temporal relationships between stroke and other factors cannot be established.

\section{BACKGROUND}

Stroke is defined as 'a neurological deficit attributed to an acute focal injury of the central nervous system (CNS) by a vascular cause'. ${ }^{1}$ Older age and male gender are associated with greater stroke risk. ${ }^{2}$ Health conditions such as hypertension, cardiovascular diseases and diabetes are established risk factors of stroke, ${ }^{3}$ whereas lifestyle factors such as smoking, alcohol consumption and obesity are found to contribute to stroke risk, some of which are dose dependent. ${ }^{4}$ Depression and dementia are also found to be associated with stroke. ${ }^{56}$

Stroke is one of the leading causes of disability and disease burden worldwide. ${ }^{7}$ Despite the global severity of stroke, stroke prevalence estimates outside Western countries, especially those from South Asian or East Asian regions are less readily available. $^{89}$ Establishing stroke prevalence estimates is important in providing feedback and planning of stroke rehabilitation and prevention, and stroke data from Asian regions 
provide a basis for comparison against Western estimates and trends. ${ }^{10}$

Singapore has a resident population of 3.93 million. ${ }^{11}$ The population comprises $74.3 \%$ Chinese, $13.4 \%$ Malay, $9.1 \%$ Indian and $3.2 \%$ other ethnicities. Singapore's population is ageing mainly due to an increase in the life expectancy-82.7 years in 2015 from 65.8 years in $1970 .^{12}$ Singapore's older adult residents (defined as Singapore citizens and permanent residents aged 65 and above) constitute $12.4 \%$ of the resident population, which is an increase from $7.2 \%$ in the year $2000 .^{113}$ The prevalence of chronic diseases including stroke is expected to be higher among this ageing population. Despite its growing importance and relevance, there exists a paucity of research on stroke prevalence in Singapore. To our knowledge, only one study (2005) was found to have reported stroke prevalence. In that study, stroke prevalence was found to be $7.67 \%$ among adults aged 65 years and above. However, since the data were collected in 2001-2003, it is unclear at this current juncture of at least a decade later, how stroke prevalence has changed in Singapore. Newer estimates can help to provide a more relevant, up-to-date understanding of stroke prevalence in a multiethnic Singapore, which can be useful in substantiating timely feedback for local public health policies and also provide a basis of relevant comparison against Western estimates and trends.

The aims of the current study were: (1) to establish the prevalence of stroke among adults aged 60 years and above in Singapore, (2) to explore the correlation of stroke with sociodemographic factors and health conditions and (3) to explore the association of stroke with disability, cognitive functioning and care needs.

\section{METHODS}

This study used data from the Well-being of the Singapore Elderly (WiSE) study which was conducted from October 2012 to December 2013. Participants provided written consent to participate in this study.

The overall sample comprised older adult Singapore residents (Singapore citizens and permanent residents) aged 60 years and above, who were living in Singapore at that point in time. Older adult residents who were institutionalised were also included in this study. Those who were not living in Singapore or who were not contactable were excluded from the study.

Sampling was conducted at random using a disproportionate stratified sampling design where the Malays and Indians, and those aged 75 and above were oversampled so as to increase precision of subgroup estimation. To ensure that the results of the WiSE study are generalisable to the older adult population in Singapore, the results were weighted against the older adult resident population of 2011 (table 1).

All participants who consented to the study were administered a series of questionnaires which comprised questions on sociodemographics, health, cognition and neurological tests in a single assessment. For each participant, an informant was also chosen and administered informant-adapted questionnaires. An informant was defined as the 'person who knows the older person best'. Some informants were caregivers while others were in close contact with the older person without a caregiving role. The face-to-face assessments were carried out based on the participants' and informants' preferred language or dialect, and these interviews were conducted by trained interviewers. Participants completed the questionnaires without influence of their informants even in cases when participants had cognitive deficits. The questionnaires were valid, reliable and made culturally relevant for the older adults in Singapore. An earlier article $^{14}$ provides further details of the study.

The main questionnaires relevant to this current analysis were:

Sociodemographic questionnaire: Participants were asked to provide sociodemographic information such as their age, gender, ethnicity, education level, and height and weight measurements.

Stroke and health conditions: Participants were asked if they had ever been told by a doctor that they had stroke. Participants were questioned in the same way for other health conditions such as hypertension, heart trouble and diabetes. Additionally, they were asked to provide more details about who diagnosed their health condition and whether they were still seeking treatment for the condition.

Smoking: Participants provided a response for the following question, 'Has there ever been a period when you smoked cigarettes, cigars, or a pipe, chewing tobacco, beedi (Indian cigarette) or snuff nearly every day?', responses were binary 0 (no) and 1 (yes) and, 'Do you still use tobacco regularly?', responses were binary 0 (no) and 1 (yes). Responses for the two questions were then categorised into 0 (non-smoker), 1 (ex-smoker) and 2 (current smoker).

Alcohol use: Participants provided responses for the following question, 'Was there ever a period in your life when you drank at least 12 drinks in a year?' Responses were 0 (never drank alcoholic drinks), 1 (no, less than 12 drinks in a year), 2 (yes, more than 12 drinks a year). Responses were recoded as 0 (never drank alcoholic drinks), original responses 1 and 2 were recoded as 1 (yes, ever drank alcoholic drinks).

Body mass index (BMI) and waist-hip ratio (WHR): BMI was calculated dividing the weight in kilograms with the square of height in metres. Those with BMI $\geq 30 \mathrm{~kg} /$ $\mathrm{m}^{2}$ were considered obese. ${ }^{15}$ WHR is a measurement of abdominal obesity, measured by a ratio of the waist circumference to the hip circumference. Men with WHR greater than 0.90 and women greater than 0.80 were considered to be obese. ${ }^{15}$

Geriatric Mental State-Automated Geriatric Examination for Computer-Assisted Taxonomy (GMS-AGECAT, Depression): A diagnostic assessment for depression as well as other 
Table 1 Descriptive characteristics of the sample population

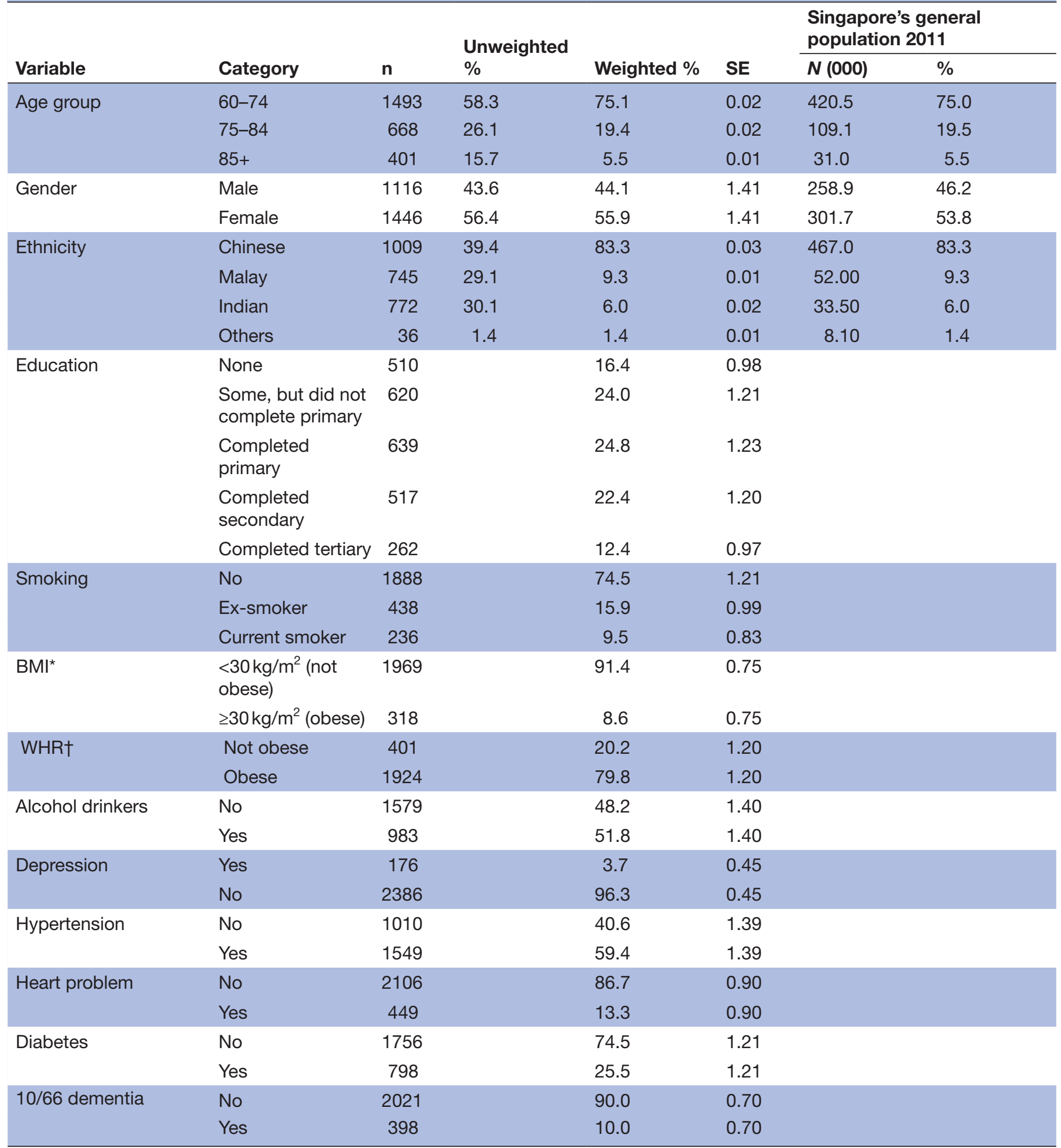

${ }^{*}$ Criteria based on WHO BMI cut-off for obesity.

†Criteria based on WHO WHR cut-off of $>0.80$ for females, $>0.90$ for males.

BMI, body mass index; GMS, Geriatric Mental State; WHR, waist-hip ratio. Depression, GMS-AGECAT.

mental illnesses that uses a computerised algorithm (AGECAT) to make diagnoses. Six levels of severity are generated from 0 (none) to 5 (severe). A severity level 0 would indicate no depression; levels 1-2 indicate subsyndromal depression, levels 3-5 indicate AGECAT depression. For the purpose of this analysis, responses were recoded as binary responses 0 (levels 0-2), 1 (levels 3 to 5). Inter-rater agreement on depression diagnoses between AGECAT and psychiatrists' achieved a kappa value of $0.88 .^{16}$ 
A cognitive test battery comprising two cognitive tests, (1) the community screening instrument for dementia (CSI'D) which incorporated the animal naming verbal fluency task by the Consortium to Establish a Registry for Alzheimer's Dementia (CERAD), and (2) a 10-word-list learning task with delayed recall by CERAD (modified). An aggregated cognitive score called the COGSCORE was generated by taking the summation of all item-weighted scores of the entire cognitive test battery.

10/66 dementia: A 10/66 dementia diagnosis was given to older adults based on a cut-off determined by logistic regression coefficients of CSI'D COGSCORE, RELSCORE (unweighted total informant score of functional and cognitive decline in the older adult), GMS/ AGECAT, and the modified CERAD. A cut-off of more than 0.25 was used as it produced the best sensitivity and specificity to identify dementia cases. ${ }^{17}$ Validation of the $10 / 66$ diagnosis revealed that it had a substantial agreement with clinician diagnosis in the WiSE study. ${ }^{14}$

WHO-Disability Assessment Schedule (WHO-DAS) 2.0: It is a 12-item questionnaire which assesses 6 domains of functioning in cognition, mobility, self-care, getting along, life activities and participation. Item responses range from 0 (no difficulty) to 4 (extremely difficulty or cannot do). A total WHO-DAS score is calculated by the summation of the domain scores.

Care need: Defined as the amount of care needed by the older person that is provided by the informant. Informants were asked to respond to whether: the older person needs care much of the time (1), needs care occasionally (2), does not need care; they are able to do everything for themselves (3).

\section{Statistical analysis}

Statistical analyses were carried out using the SAS system V.9.3. All of the statistical analyses used in this study were based on weighted data. First, simple logistic regression was used to analyse the correlates of stroke prevalence at a univariate level. Second, multiple logistic regression was used to analyse sociodemographic and health correlates of stroke at a multivariate level. Sociodemographic factors such as age group, gender, ethnicity, education and health or lifestyle conditions such as hypertension, heart trouble, diabetes, smoking, alcohol use, depression and dementia were used as predictors in both regression analyses. Associations with cognitive and disability scores were estimated using multiple linear regressions, while association with care needs was estimated using multinomial logistic regression after accounting for covariates. Missing answers were deleted listwise. Statistical significance was set at a conventional cut-off point at $\mathrm{p}<0.05$, two tailed.

The target sample size was determined by a power calculation for binary proportions. After adjusting for design effect for the overall prevalence estimate, subgroups by age and ethnicity with the precision of $5 \%$, it was estimated that a sample size of 2500 was sufficient in providing adequate precision. ${ }^{14}$

\section{RESULTS}

The characteristics of the sample population are summarised in table 1 . The overall response rate was 65.6 $\%(2565 / 3913)$. In all, 2562 participants were included in the current analysis (3 missing answers were removed listwise). The mean age was approximately 70 years old $(\mathrm{M}=69.9, \mathrm{SD}=7.84)$. Participants comprised $44.1 \%$ males and $55.9 \%$ females. The sample comprised $83.3 \%$ Chinese, 9.3\% Malay, 6\% Indian and other ethnicities $1.4 \%$.

Out of 2562 older adult participants, 199 respondents reported that they had ever been told by a doctor to have had stroke. The overall weighted stroke prevalence was $7.6 \%,(95 \%$ CI $6.2 \%$ to $9.0 \%)$ among older adult residents aged 60 years and above. Weighted stroke prevalence for those aged 65 years and above was $9.3 \%$. A detailed breakdown of the prevalence of stroke by sociodemographic and health variables are presented in table 2 .

\section{Sociodemographic and health correlates of stroke}

Simple logistic regression revealed that sociodemographic features such as older age, no education, ex-smokers were associated with higher stroke prevalence $(\mathrm{p}<0.05)$. Stroke was 2.4 times higher in the 75-84 age group, and three times higher in the above 85 years old age group as compared with the younger age group 60-74. Stroke was three times higher in those who self-reported no education than those who had completed tertiary education. Stroke was two times higher among ex-smokers than those who had never smoked. Malay ethnicity was associated with lower stroke prevalence $(\mathrm{p}<0.05)$, having 0.6 times lower odds of having stroke as compared to Chinese ethnicity.

Health conditions such as hypertension, heart trouble, diabetes, and dementia significantly predicted stroke prevalence $(\mathrm{p}<0.001)$ at the univariate level. Stroke was higher among those who self-reported having hypertension (4.5 times), heart trouble (4.3 times), diabetes (2.7 times) and dementia (8 times) as compared with those without the respective health conditions. Gender, obesity (BMI and WHR), alcohol consumption and depression were not associated with stroke in this study.

Multivariate logistic regression revealed that only hypertension, heart trouble, diabetes and 10/66 dementia were independently associated with higher stroke prevalence $(\mathrm{p}<0.05)$. At the multivariate level, stroke was higher among those with self-reported hypertension (4.6 times), heart trouble (2.5 times), diabetes (2.6 times) and 10/66 dementia (3.6 times) as compared with those without the respective health conditions. Ethnic differences maintained significance at the multivariate level-ethnic Malays had significantly lower odds $(\mathrm{OR}=0.4)$ of stroke when compared with ethnic Chinese. There was no significant difference in stroke prevalence between those of Indian and Chinese ethnicities.

Age group, gender, education, depression and other lifestyle (smoking, alcohol, BMI and WHR) conditions were not associated with stroke prevalence $(p>0.05)$ at a multivariate 
Table 2 Number of stroke and non-stroke cases by sociodemographic and health factors

\begin{tabular}{|c|c|c|c|c|c|c|c|}
\hline \multirow[b]{2}{*}{ Variable } & \multirow[b]{2}{*}{ Category } & \multicolumn{3}{|c|}{ Without stroke } & \multicolumn{3}{|c|}{ Stroke } \\
\hline & & $\mathbf{n}$ & $\%$ & SE & n & $\%$ & SE \\
\hline \multirow[t]{3}{*}{ Age group } & $60-74$ & 1415 & 94.3 & 0.8 & 78 & 5.7 & 0.8 \\
\hline & $75-84$ & 599 & 87.4 & 1.8 & 69 & 12.6 & 1.8 \\
\hline & $85+$ & 349 & 84.5 & 2.4 & 52 & 15.5 & 2.4 \\
\hline \multirow[t]{2}{*}{ Gender } & Male & 1033 & 92 & 1.1 & 83 & 8 & 1.1 \\
\hline & Female & 1330 & 92.7 & 0.9 & 116 & 7.3 & 0.9 \\
\hline \multirow[t]{4}{*}{ Ethnicity } & Chinese & 913 & 92.2 & 0.8 & 96 & 7.8 & 0.8 \\
\hline & Malay & 704 & 94.9 & 0.9 & 41 & 5.1 & 0.9 \\
\hline & Indian & 715 & 93.7 & 0.9 & 57 & 6.3 & 0.9 \\
\hline & Others & 31 & 85.6 & 6.1 & 5 & 14.4 & 6.1 \\
\hline \multirow[t]{5}{*}{ Education } & None & 455 & 87.8 & 2.1 & 55 & 12.2 & 2.1 \\
\hline & $\begin{array}{l}\text { Some, but did not } \\
\text { complete primary }\end{array}$ & 566 & 91.8 & 1.5 & 54 & 8.2 & 1.5 \\
\hline & $\begin{array}{l}\text { Completed } \\
\text { primary }\end{array}$ & 596 & 93.4 & 1.4 & 43 & 6.6 & 1.4 \\
\hline & $\begin{array}{l}\text { Completed } \\
\text { secondary }\end{array}$ & 485 & 93.7 & 1.4 & 32 & 6.3 & 1.4 \\
\hline & $\begin{array}{l}\text { Completed } \\
\text { tertiary }\end{array}$ & 249 & 95.5 & 1.7 & 13 & 4.5 & 1.7 \\
\hline \multirow[t]{3}{*}{ Smoking } & No & 1749 & 93.2 & 0.8 & 139 & 6.8 & 0.8 \\
\hline & Ex-smoker & 393 & 87.7 & 2.2 & 45 & 12.3 & 2.2 \\
\hline & Current smoker & 221 & 93.8 & 2.2 & 15 & 6.2 & 2.2 \\
\hline \multirow[t]{2}{*}{$\mathrm{BMI}^{*}$} & $\begin{array}{l}<30 \mathrm{~kg} / \mathrm{m}^{2} \text { (not } \\
\text { obese) }\end{array}$ & 1850 & 94.1 & 0.7 & 119 & 5.9 & 0.7 \\
\hline & $\geq 30 \mathrm{~kg} / \mathrm{m}^{2}$ (obese) & 304 & 94.1 & 2.3 & 14 & 5.9 & 2.3 \\
\hline \multirow[t]{2}{*}{ WHR† } & Not obese & 382 & 96 & 1.2 & 19 & 4 & 1.2 \\
\hline & Obese & 1809 & 93.5 & 0.8 & 115 & 6.5 & 0.8 \\
\hline \multirow{2}{*}{$\begin{array}{l}\text { Alcohol } \\
\text { drinkers }\end{array}$} & No & 1451 & 91.4 & 1.1 & 128 & 8.6 & 1.1 \\
\hline & Yes & 912 & 93.3 & 1 & 71 & 6.7 & 1 \\
\hline \multirow[t]{2}{*}{ Depression } & Yes & 156 & 86.7 & 4.5 & 20 & 13.3 & 4.5 \\
\hline & No & 2207 & 92.6 & 0.7 & 179 & 7.4 & 0.7 \\
\hline \multirow[t]{2}{*}{ Hypertension } & No & 972 & 97.3 & 0.7 & 38 & 2.7 & 0.7 \\
\hline & Yes & 1388 & 89 & 1.1 & 161 & 11 & 1.1 \\
\hline \multirow[t]{2}{*}{ Heart problem } & No & 1981 & 94.4 & 0.7 & 125 & 5.6 & 0.7 \\
\hline & Yes & 377 & 79.8 & 2.9 & 72 & 20.2 & 2.9 \\
\hline \multirow[t]{2}{*}{ Diabetes } & No & 1657 & 94.5 & 0.7 & 99 & 5.5 & 0.7 \\
\hline & Yes & 699 & 86.3 & 1.8 & 99 & 13.7 & 1.8 \\
\hline \multirow{2}{*}{$\begin{array}{l}\text { 10/66 } \\
\text { dementia }\end{array}$} & No & 1913 & 94.9 & 0.7 & 108 & 5.1 & 0.7 \\
\hline & Yes & 214 & 69.7 & 3.7 & 84 & 30.3 & 3.7 \\
\hline
\end{tabular}

${ }^{*}$ Criteria based on WHO BMI cut-off for obesity.

†Criteria based on WHO WHR cut-off of $>0.80$ for females, $>0.90$ formales.

BMI, body mass index; WHR, waist-hip ratio; Depression, GMS-AGECAT.

level. The complete results of the sociodemographic and health correlates of stroke are presented in table 3 .

Cognition, disability and care needs correlates of stroke After adjusting for sociodemographic and health covariates in multiple linear regression analyses, stroke was negatively associated with cognitive scores $(\beta=-1.15$, $\mathrm{p}=0.011)$ and positively associated with disability scores $(\beta=9.01, p<0.001)$. This meant that respondents with stroke were associated with greater cognitive deficits as well as greater physical disabilities.

After adjusting for covariates in multinomial logistic regression analysis, stroke and care needs 
Table 3 Sociodemographic and health correlates of stroke

\begin{tabular}{|c|c|c|c|c|c|c|c|}
\hline \multirow[b]{2}{*}{ Variable } & \multirow[b]{2}{*}{ Categories } & \multicolumn{3}{|c|}{ Simple logistic regression } & \multicolumn{3}{|c|}{ Multiple logistic regression } \\
\hline & & OR & $\begin{array}{l}95 \% \text { Wald } \\
\mathrm{Cl}\end{array}$ & $P$ values & OR & $\begin{array}{l}95 \% \text { Wald } \\
\mathrm{Cl}\end{array}$ & $P$ values \\
\hline \multirow{2}{*}{ Age group } & $75-84$ & 2.38 & 1.54 to 3.69 & $<0.001$ & 1.23 & 0.67 to 2.25 & 0.498 \\
\hline & $85+$ & 3.04 & 1.90 to 4.87 & $<0.001$ & 0.79 & 0.31 to 2.02 & 0.627 \\
\hline \multirow[t]{4}{*}{ Ethnicity } & Chinese & Reference & & & Reference & & \\
\hline & Malay & 0.63 & 0.41 to 0.96 & 0.030 & 0.41 & 0.20 to 0.82 & 0.012 \\
\hline & Indian & 0.79 & 0.55 to 1.15 & 0.217 & 0.61 & 0.33 to 1.11 & 0.103 \\
\hline & Others & 1.98 & 0.74 to 5.36 & 0.176 & 2.71 & 0.81 to 9.13 & 0.107 \\
\hline \multirow{3}{*}{ Education } & $\begin{array}{l}\text { Completed } \\
\text { primary }\end{array}$ & 1.50 & 0.60 to 3.74 & 0.388 & 1.66 & 0.49 to 5.69 & 0.418 \\
\hline & $\begin{array}{l}\text { Completed } \\
\text { secondary }\end{array}$ & 1.43 & 0.57 to 3.62 & 0.447 & 1.30 & 0.42 to 4.10 & 0.651 \\
\hline & $\begin{array}{l}\text { Completed } \\
\text { tertiary }\end{array}$ & Reference & & & Reference & & \\
\hline \multirow[t]{2}{*}{ Smoking } & Non-smoker & Reference & & & Reference & & \\
\hline & Ex-smoker & 1.94 & 1.22 to 3.10 & 0.006 & 1.75 & 0.80 to 3.82 & 0.160 \\
\hline \multirow[t]{2}{*}{ Alcohol drinkers } & No & Reference & & & Reference & & \\
\hline & Yes & 0.77 & 0.51 to 1.15 & 0.201 & 0.56 & 0.30 to 1.06 & 0.076 \\
\hline \multirow[t]{2}{*}{ Depression } & No & Reference & & & Reference & & \\
\hline & Yes & 1.92 & 0.87 to 4.26 & 0.109 & 0.76 & 0.21 to 2.84 & 0.687 \\
\hline \multirow[t]{2}{*}{ Hypertension } & No & Reference & & & Reference & & \\
\hline & Yes & 4.52 & 2.55 to 8.00 & $<0.001$ & 4.58 & 1.84 to 11.40 & 0.001 \\
\hline \multirow[t]{2}{*}{ Heart trouble } & No & Reference & & & Reference & & \\
\hline & Yes & 4.25 & 2.75 to 6.58 & $<0.001$ & 2.45 & 1.30 to 4.63 & 0.006 \\
\hline \multirow[t]{2}{*}{ Diabetes } & No & Reference & & & Reference & & \\
\hline & Yes & 2.72 & 1.80 to 4.12 & $<0.001$ & 2.60 & 1.49 to 4.53 & 0.001 \\
\hline \multirow[t]{2}{*}{ 10/66 Dementia } & No & Reference & & & Reference & & \\
\hline & Yes & 8.06 & 5.19 to 12.52 & $<0.001$ & 3.57 & 1.57 to 8.12 & 0.002 \\
\hline
\end{tabular}

${ }^{*}$ Criteria based on WHO BMI cut-off for obesity.

†Criteria based on WHO WHR cut-off of $>0.80$ for females, $>0.90$ for males.

BMI, body mass index; WHR, waist-hip ratio; Depression, GMS AGECAT.

were found to be positively associated $(\mathrm{p}<0.001)$. Among older adults with stroke, there was a 4 and 10 times increase in the odds of needing care 'occasionally' and 'much of the time', respectively, when compared with those without stroke The results of the correlates of stroke with cognitive, disability scores and care needs are presented together in table 4 . 
Table 4 Relationship between stroke and cognitive, WHO-DAS, and care needs scores

\begin{tabular}{|c|c|c|c|c|c|c|c|c|c|c|}
\hline \multirow{2}{*}{$\begin{array}{l}\text { Cognitive and } \\
\text { disability scores }\end{array}$} & \multicolumn{3}{|c|}{ Without stroke } & \multicolumn{3}{|c|}{ With stroke } & \multirow[b]{2}{*}{$\mathrm{B}^{*}$} & \multirow[b]{2}{*}{ SE } & \multirow[b]{2}{*}{$P$ values } & \multirow[b]{2}{*}{$95 \% \mathrm{Cl}$} \\
\hline & $\mathrm{n}$ & Mean & SE & $n$ & Mean & SE & & & & \\
\hline $\begin{array}{l}\text { Cognitive score } \\
\text { (COGSCORE) }\end{array}$ & 2363 & 28.6 & 0.09 & 199 & 22.6 & 0.91 & -1.15 & 0.45 & 0.011 & -2.04 to -0.27 \\
\hline \multirow[t]{2}{*}{ WHO-DAS } & 2363 & 8.70 & 0.36 & 199 & 37.0 & 3.26 & 9.01 & 2.07 & $<0.001$ & 4.96 to 13.07 \\
\hline & $\mathbf{n}$ & $\%$ & SE & $\mathbf{n}$ & $\%$ & SE & ORt & SE & $P$ values & $95 \% \mathrm{Cl}$ \\
\hline $\begin{array}{l}\text { Needs care much } \\
\text { of the time }\end{array}$ & 237 & 57.7 & 4.40 & 92 & 42.3 & 4.40 & 10.1 & 0.43 & $<0.001$ & 4.35 to 23.31 \\
\hline $\begin{array}{l}\text { Needs care } \\
\text { occasionally }\end{array}$ & 320 & 84.3 & 3.11 & 43 & 15.7 & 3.11 & 4.09 & 0.40 & $<0.001$ & 1.86 to 9.01 \\
\hline Does not need care & 1670 & 96.5 & 0.61 & 57 & 3.50 & 0.61 & Reference & & & \\
\hline
\end{tabular}

${ }^{*} \mathrm{~B}$ coefficient derived from multiple linear regression analysis after adjusting for sociodemographic and health covariates. †OR derived from multinomial logistic regression analyses after adjusting for sociodemographic and health covariates. WHO-DAS, WHO-Disability Assessment Schedule.

\section{DISCUSSION}

\section{Stroke prevalence}

The weighted stroke prevalence found in this study was $7.6 \%$ among the older adults aged 60 and above. In an earlier population-based study that was conducted in Singapore in the year 2001-2003, stroke prevalence among older adults aged 65 and above was found to be $7.7 \% .^{18}$ For the purpose of comparison, weighted stroke prevalence among those 65 years and above was found to be $9.3 \%$ in this study, which was higher as compared with the figures reported by the earlier study. ${ }^{18}$

Stroke prevalence found in this study was comparable to the figures reported in Western populations, such as $8.3 \%$ in the USA among older adults 65 years and above. ${ }^{19}$ However, the figures were higher than that reported in several non-Western ageing populations, such as $4.5 \%$ in Korea ${ }^{20} 4.9 \%$ in Hong Kong ${ }^{21}$ and $2.7 \%$ in Thailand ${ }^{22}$ among older adults aged 65 years and above.

In the previous study, stroke prevalence among the three major ethnic groups (Chinese, Malay, Indian) was found to range from $3.32 \%$ to $3.75 \% .{ }^{18}$ Chinese ranked the highest in prevalence, followed by Indian and Malay ethnicities. While the ranking remained the same in this study, there was an increase in stroke prevalence across all three ethnic groups, ranging from $5.1 \%$ to $7.8 \%$. While the previous study did not find ethnic differences in stroke prevalence, the WiSE study found significant differences between the Chinese and Malay ethnicities with ethnic Malays having significantly lower stroke prevalence as compared with ethnic Chinese. These results were unexpected because according to the National Health Survey (2010), Malay ethnicity has been associated with various stroke risk factors such as hypertension and obesity. ${ }^{23}$ There appears to be no clear explanations for our findings, however, as it was previously reported that ethnic minority groups, such as Malays, have a lower tendency of self-rating poor health, ${ }^{24}$ it is possible that either they did not want to mention being diagnosed, they were not diagnosed or did not remember being diagnosed with stroke. Additionally, according to the Singapore's census population statistics (2010), it has been reported that those belonging to the Malay ethnic group have the lowest median household income. ${ }^{25}$ Thus, it could be possible that they have fewer opportunities to be informed about their health, which could also explain the lower self-reported stroke. As stroke prevalence data in Singapore is scarce, comparisons with past studies are insufficient, thereby making it difficult to draw sound conclusions. Future research could take into account any administrative data or registries to draw clearer outcomes on ethnic differences in stroke epidemiology.

\section{Sociodemographic correlates of stroke}

Age was significantly associated with stroke prevalence at a univariate level, a finding that was consistent with past research. ${ }^{18}{ }^{26}$ After controlling for sociodemographic and health conditions, however, the association disappeared. These findings were consistent with an earlier study that examined stroke risk factors and stroke prevalence among Thai adults aged $45-80$ years, where older age was not associated with higher stroke prevalence after all other factors were considered. ${ }^{22}$ Unexpectedly, gender was not associated with stroke prevalence in this study and it is unclear why this is so.

Biological changes that come with old age may affect existing age/gender association with stroke risk factors, which in turn may contribute to the lack of association between age/gender and stroke prevalence. Hypertension, diabetes and cardiovascular complications usually arise with increasing age. For instance, increased high blood pressure is greatly attributed to the changes to the cardiovascular system, structure of arteries and large artery stiffness that come with age. ${ }^{2728}$ Cardiovascular problems and diabetes are usually associated with thesedentary lifestyle of old age. ${ }^{29} 30$ By the age of 60-69 years, women have a higher risk of developing hypertension due to menopause. ${ }^{31}$ However, research has also shown that certain health conditions become less prevalent with increasing age. In one study, existing age/ 
gender associations with several stroke risk factors tend to diminish or change among older age groups ( $70-80$ years) and especially for men. ${ }^{32}$ Our findings suggest that health complications that come with age and gender may have been better predictors of stroke prevalence among older adults in this study.

\section{Health correlates of stroke}

The WiSE study found that hypertension, heart trouble and diabetes were independently associated with stroke prevalence. These findings were expected since these health conditions are established determinants of stroke. ${ }^{3}$ Stroke was also associated with 10/66 dementia, which is also an expected finding since stroke and Alzheimer's disease have various overlapping risk characteristics. ${ }^{1733}$

Obesity was not associated with stroke prevalence. While it was not unexpected that there was no association between BMI and stroke risk, WHR was an unexpected finding since WHR was found to be a stronger predictor of stroke risk than BMI. ${ }^{34}{ }^{35}$ Our findings, however, were similar to the aforementioned study among Thai older adults. In both studies, BMI was not a significant predictor at a univariate level and WHR did not independently predict stroke prevalence at a multivariate level. ${ }^{22}$ Having ever smoked (current and ex-smokers) and alcohol consumption were not associated with stroke prevalence among older adult residents. These results were unanticipated, however, as research has shown that these factors are dose dependent, ${ }^{36-39}$ it could be possible that the sample of older adult respondents in this study were not heavy smokers and did not consume alcohol excessively.

Stroke prevalence was not associated with depression in this study. Our finding differed from several other existing studies and meta-analyses which found otherwise. ${ }^{5}$ Although meta-analyses have shown a positive association, majority of the studies included in these meta-analyses did not take into account stroke risk factors such as BMI or alcohol use. ${ }^{41}$ The results of this study were consistent with at least one prospective study which found that depression was not associated with stroke risk among older adults, after adequately controlling for covariates. ${ }^{42} 43$ Taken together, depression did not appear to be a relevant risk factor of stroke in older adults.

\section{Stroke, disability and care need}

As expected, stroke was found to be associated with low cognitive and high disability scores. Stroke is among the top three leading cause of disability among older adults aged 65 years and above in Singapore and involves longterm dependency on healthcare services. ${ }^{44}$ Despite the severity of stroke disability, a substantial number of stroke patients tend not go for poststroke therapy citing high financial costs, inconvenience and lack of interest. ${ }^{45}$

Our study revealed stroke to be associated with greater care needs. In Singapore, given that close to $95 \%$ of older adult residents stay with family members ${ }^{46}$ and that age-related diseases will rise in view of the ageing population in Singapore, it is expected that there will be a substantial increase in burden and reliance on family members for their daily needs if disabled. These findings, thus, indicate the need to extend and improve on existing services to stroke survivors and to caregivers.

This study has some limitations, with foremost the nature of self-reported stroke which may be subjected to errors such as false reporting resulting in overestimation or underestimation of stroke prevalence. However, most population-based prevalence studies use self-report for ease of administration, cost-effectiveness and for direct comparison with the majority of studies which used similar methods. Third, as this is a cross-sectional study, temporal relationships between stroke and other factors cannot be established.

Future research should take into consideration the importance of establishing stroke incidence to provide a well-informed understanding of stroke epidemiology in Singapore. Published research articles on stroke incidence in Singapore are rare-the most recent study was published in the year 2000. ${ }^{47}$ In Adelaide, possibly owing to advances in healthcare intervention and public initiatives, stroke incidence rates have declined despite an ageing population. ${ }^{48}{ }^{49}$ At the present juncture, it remains unclear whether recent incidence estimates of stroke have increased or decreased in Singapore relative to past data and worldwide.

\section{CONCLUSION}

The prevalence of stroke survivors in Singapore is relatively high when compared with other Asian countries. Our findings provide support for the existing body of research on stroke prevalence and its correlates. Given that Singapore's population is ageing rapidly, our findings may indicate a need to review existing support services for stroke survivors and their caregivers. Finally, future research could take into consideration incidence rates for more relevant understanding of stroke epidemiology in Singapore, and also investigate the role of gender, ethnicity and lifestyle risk factors such as smoking, alcohol use and obesity on stroke prevalence to confirm the findings of this study.

Contributors WLT wrote the first draft of the manuscript. EA provided statistical analysis. JAV, ELSS, VS, SShafie, SShahwan and YJZ were involved in data collection and literature review searches. MS and SAC wrote the protocol and designed the study. LLN provided intellectual input in the area of data collection and analyses. All authors contributed and approved the final manuscript.

Funding The study was funded by the Ministry of Health, Singapore and the Singapore Millennium Foundation of the Temasek Trust.

Competing interests None declared.

Patient consent Obtained.

Ethics approval National Healthcare Group Domain Specific Review Board and the SingHealth Centralised Institutional Review Board.

Provenance and peer review Not commissioned; externally peer reviewed.

Data sharing statement Data are not available for online access; however, readers who wish to gain access to the data can write to the senior author (MS) at mythily@imh.com.sg with their requests. Access can be granted and subjected to the Institutional Review Board (IRB) and the research collaborative agreement guidelines. This is a requirement mandated for this research study by our IRB and funders. 
Open Access This is an Open Access article distributed in accordance with the Creative Commons Attribution Non Commercial (CC BY-NC 4.0) license, which permits others to distribute, remix, adapt, build upon this work non-commercially, and license their derivative works on different terms, provided the original work is properly cited and the use is non-commercial. See: http://creativecommons.org/ licenses/by-nc/4.0/

(c) Article author(s) (or their employer(s) unless otherwise stated in the text of the article) 2018. All rights reserved. No commercial use is permitted unless otherwise expressly granted.

\section{REFERENCES}

1. Sacco RL, Kasner SE, Broderick JP, et al. An updated definition of stroke for the 21st century: a statement for healthcare professionals from the American Heart Association/American Stroke Association. Stroke 2013;44:2064-89.

2. Sacco RL, Benjamin EJ, Broderick JP, et al. Risk factors. Stroke 1997;28:1507-17.

3. O'Donnell MJ, Xavier D, Liu L, et al. Risk factors for ischaemic and intracerebral haemorrhagic stroke in 22 countries (the INTERSTROKE study): a case-control study. Lancet 2010;376:112-23.

4. Gorelick PB, Sacco RL, Smith DB, et al. Prevention of a first stroke: a review of guidelines and a multidisciplinary consensus statement from the National Stroke Association. JAMA 1999;281:1112-20.

5. Dong JY, Zhang YH, Tong J, et al. Depression and risk of stroke: a meta-analysis of prospective studies. Stroke 2012;43:32-7.

6. Pendlebury ST, Rothwell PM. Prevalence, incidence, and factors associated with pre-stroke and post-stroke dementia: a systematic review and meta-analysis. Lancet Neurol 2009;8:1006-18.

7. Bonita R, Mendis S, Truelsen T, et al. The global stroke initiative. Lancet Neurol 2004;3:391-3.

8. Burke TA, Venketasubramanian RN. The epidemiology of stroke in the East Asian region: a literature-based review. Int J Stroke 2006;1:208-15.

9. Mehndiratta MM, Khan M, Mehndiratta P, et al. Stroke in Asia: geographical variations and temporal trends. J Neurol Neurosurg Psychiatry 2014;85:1308-12.

10. Tan K, Wong K, Venketasubramanian N. Setting priorities in Asian stroke research. Neurology Asia 2006;11:5-11.

11. Department of Statistics Singapore. Population Trends 2016. In., vol. 2016. Singapore. http://www.singstat.gov.sg/docs/default-source/ default-document-library/publications/publications_and_papers/ population_and_population_structure/population2016.pdf (accessed 26 Nov 2016).

12. Department of Statistics Singapore. Complete life tables 2014-2015 for Singapore resident population. In., vol. 2016. Singapore. http:// www.singstat.gov.sg/docs/default-source/default-document-library/ publications/publications_and_papers/births_and_deaths/lifetable1415.pdf (accessed 26 Nov 2016).

13. Department of Statistics Singapore. Census of population 2010. In. vol. 3. https://www.singstat.gov.sg/docs/default-source/defaultdocument-library/publications/publications_and_papers/cop2010/ census_2010_release1/cop2010sr1.pdf (accessed 26 Nov 2016).

14. Subramaniam M, Chong SA, Vaingankar JA, et al. Prevalence of Dementia in People Aged 60 Years and Above: Results from the WiSE Study. J Alzheimers Dis 2015;45:1127-38.

15. World Health Organization. Waist circumference and waist-hip ratio: report of a WHO expert consultation. Geneva, 2008.

16. Kua EH. A community study of mental disorders in elderly Singaporean Chinese using the GMS-AGECAT package. Aust N Z J Psychiatry 1992;26:502-6.

17. Prince M, Ferri CP, Acosta D, et al. The protocols for the $10 / 66$ dementia research group population-based research programme. BMC Public Health 2007;7:165

18. Venketasubramanian N, Tan LC, Sahadevan S, et al. Prevalence of stroke among Chinese, Malay, and Indian Singaporeans: a community-based tri-racial cross-sectional survey. Stroke 2005;36:551-6.

19. Centers for Disease Control and Prevention (CDC). Prevalence of stroke--United States, 2006-2010. : Morbidity and mortality weekly report, 2012:61: 379 .

20. Hong KS, Bang OY, Kang DW, et al. Stroke statistics in Korea: part I. Epidemiology and risk factors: a report from the korean stroke society and clinical research center for stroke. J Stroke 2013;15:2.

21. Yu R, Chau PH, McGhee SM, et al. Trends of disease burden consequent to stroke in older persons in Hong Kong: Implications of population ageing: The Hong Kong Jockey Club, 2012.
22. Hanchaiphiboolkul S, Poungvarin N, Nidhinandana S, et al. Prevalence of stroke and stroke risk factors in Thailand: Thai Epidemiologic Stroke (TES) Study. J Med Assoc Thai 2011;94:427.

23. Ministry of Health Singapore. Epidemiology and disease control division National Health Survey 2010. 2011 https://www.moh.gov.sg/ content/dam/moh_web/Publications/Reports/2011/NHS2010\%20-\% 20low\%20res.pdf (accessed 26 Nov 2016).

24. Lim WY, Ma S, Heng D, et al. Gender, ethnicity, health behaviour \& self-rated health in Singapore. BMC Public Health 2007;7:184.

25. Singapore Census of Population. Statistical Release 2: Households and Housing. 2018 (accessed 15 Jan 2018).

26. Wu X, Zhu B, Fu L, et al. Prevalence, incidence, and mortality of stroke in the chinese island populations: a systematic review. PLoS One 2013;8:e78629.

27. Pinto E. Blood pressure and ageing. Postgrad Med J 2007;83:109-14.

28. Susic D, Frohlich ED. The aging hypertensive heart: a brief update. Nat Clin Pract Cardiovasc Med 2008;5:104-10.

29. DiPietro L. Physical activity in aging: changes in patterns and their relationship to health and function. J Gerontol A Biol Sci Med Sci 2001;56 Spec No 2(suppl_2):13-22.

30. Prohaska T, Belansky E, Belza B, et al. Physical activity, public health, and aging: critical issues and research priorities. J Gerontol B Psychol Sci Soc Sci 2006;61:S267-S273.

31. Reckelhoff JF. Gender differences in the regulation of blood pressure. Hypertension 2001;37:1199-208.

32. Andersen KK, Andersen ZJ, Olsen TS. Age- and gender-specific prevalence of cardiovascular risk factors in 40,102 patients with first-ever ischemic stroke: a Nationwide Danish Study. Stroke 2010;41:2768-74.

33. Honig LS, Tang MX, Albert S, et al. Stroke and the risk of Alzheimer disease. Arch Neurol 2003;60:1707-12.

34. Bodenant M, Kuulasmaa K, Wagner A, et al. Measures of abdominal adiposity and the risk of stroke: the MOnica Risk, Genetics, Archiving and Monograph (MORGAM) study. Stroke 2011;42:2872-7.

35. Walker SP, Rimm EB, Ascherio A, et al. Body size and fat distribution as predictors of stroke among US men. Am J Epidemiol 1996;144:1143-50.

36. Rodgers H, Greenaway J, Davies T, et al. Risk factors for first-ever stroke in older people in the north East of England: a populationbased study. Stroke 2004;35:7-11.

37. Snow WM, Murray R, Ekuma O, et al. Alcohol use and cardiovascular health outcomes: a comparison across age and gender in the Winnipeg Health and Drinking Survey Cohort. Age Ageing 2009;38:206-12.

38. Camargo CA. Moderate alcohol consumption and stroke. The epidemiologic evidence. Stroke 1989;20:1611-26.

39. Kelly TN, Gu D, Chen J, et al. Cigarette smoking and risk of stroke in the chinese adult population. Stroke 2008;39:1688-93.

40. Pan A, Sun Q, Okereke OI, et al. Depression and risk of stroke morbidity and mortality: a meta-analysis and systematic review. JAMA 2011;306:1241-9.

41. Moise N, Khodneva Y, Richman J, et al. Elucidating the Association Between Depressive Symptoms, Coronary Heart Disease, and Stroke in Black and White Adults: The REasons for Geographic And Racial Differences in Stroke (REGARDS) Study. J Am Heart Assoc 2016;5:e003767

42. Salaycik KJ, Kelly-Hayes M, Beiser A, et al. Depressive symptoms and risk of stroke: the Framingham Study. Stroke 2007;38:16-21.

43. Köhler S, Verhey F, Weyerer S, et al. Depression, non-fatal stroke and all-cause mortality in old age: a prospective cohort study of primary care patients. J Affect Disord 2013;150:63-9.

44. Epidemiology \& Disease Control Division. Singapore burden of disease study 2010. Singapore: Ministry of Health, 2014. https:// www.moh.gov.sg/content/dam/moh_web/Publications/Reports/ 2014/Singapore\%20Burden\%20of\%20Disease\%20Study\% 202010\%20Report v3.pdf (accessed 26 Nov 2016).

45. Chen AW, Koh YT, Leong SW, et al. Post community hospital discharge rehabilitation attendance: Self-perceived barriers and participation over time. Ann Acad Med Singapore 2014;43:136-44.

46. Mehta KK. Stress among family caregivers of older persons in Singapore. J Cross Cult Gerontol 2005;20:319-34.

47. Heng DM, Lee J, Chew SK, et al. Incidence of ischaemic heart disease and stroke in Chinese, Malays and Indians in Singapore: Singapore Cardiovascular Cohort Study. Ann Acad Med Singapore 2000;29:231-6

48. Leyden JM, Kleinig TJ, Newbury J, et al. Adelaide stroke incidence study: declining stroke rates but many preventable cardioembolic strokes. Stroke 2013;44:1226-31.

49. Newbury J, Kleinig T, Leyden J, et al. Stroke Epidemiology in an Australian Rural Cohort (SEARCH). Int J Stroke 2017;12:161-8. 